\title{
Mouse Oocyte Control of Granulosa Cell Development and Function: Paracrine Regulation of Cumulus Cell Metabolism
}

\author{
You-Qiang Su, Ph.D.,' ${ }^{1}$ Koji Sugiura, Ph.D., ${ }^{1}$ and John J. Eppig, Ph.D. ${ }^{1}$
}

ABSTRACT

Bidirectional communication between oocytes and the companion granulosa cells is essential for the development and functions of both compartments. Oocytes are deficient in their ability to transport certain amino acids and in carrying out glycolysis and cholesterol biosynthesis. Cumulus cells must provide them with the specific amino acids and the products in these metabolic pathways. Oocytes control metabolic activities in cumulus cells by promoting the expression of genes in cumulus cells encoding specific amino acid transporters and enzymes essential for the oocyte-deficient metabolic processes. Hence oocytes outsource metabolic functions to cumulus cells to compensate for oocyte metabolic deficiencies. Oocyte control of granulosa cell metabolism may also participate in regulating the rate of follicular development in coordination with endocrine, paracrine, and autocrine signals. Oocytes influence granulosa cell development mainly by secretion of paracrine factors, although juxtacrine signals probably also participate. Key oocyte-derived paracrine factors include growth differentiation factor 9 , bone morphogenetic protein 15 , and fibroblast growth factor $8 \mathrm{~B}$.

KEYWORDS: Oocytes, cumulus cells, metabolisms, oocyte-derived factors

\begin{abstract}
A crucial objective of folliculogenesis is the production of a fertilizable egg competent to undergo activation and embryogenesis. To achieve this goal, precise coordination between the germinal and somatic compartments of the follicle is required in responding to endocrine, paracrine, and autocrine signals, as well as those communicated by the gap junctions that link granulosa cells and the oocyte. Hence bidirectional communication between oocytes and companion somatic cells is essential for the development and function of both follicular compartments. ${ }^{1}$ Granulosa cells have long been known to play a nurturing role in supporting oocyte development by providing essential nutrients to oocytes. ${ }^{2}$ Granulosa cells also participate in
\end{abstract}

maintenance of oocyte meiotic arrest, global suppression of oocyte transcriptional activity, and the induction of oocyte meiotic and cytoplasmic maturation. ${ }^{3}$ Oocytes, in contrast, play active roles in the regulation of the development and function of granulosa cells throughout the course of folliculogenesis. Oocytes affect the formation and activation of the primordial follicle pool in the ovary as evidenced by the targeted deletion of Figla (folliculogenesis-specific basic helix-loop-helix ${ }^{4}$ and oocyte-specific knockout of Pten (phosphatase and tensin homolog deleted on chromosome 10, a gene encoding a major negative phosphatidylinositol 3-kinase), ${ }^{5}$ which cause failure of primordial follicle formation ${ }^{4}$ and activation of the entire primordial follicle pool and consequent
${ }^{1}$ The Jackson Laboratory, Bar Harbor, Maine.

Address for correspondence and reprint requests: You-Qiang Su, Ph.D., The Jackson Laboratory, 600 Main Street, Bar Harbor, ME 04609 (e-mail: youqiang.su@jax.org).

Growth Factors and the Development and Function of the Reproductive Organs; Guest Editors, Linda C. Giudice, M.D.,
Ph.D., and Marco Conti, M.D.

Semin Reprod Med 2009;27:32-42. Copyright (C) 2009 by Thieme Medical Publishers, Inc., 333 Seventh Avenue, New York, NY 10001, USA. Tel: +1(212) 584-4662.

DOI 10.1055/s-0028-1108008. ISSN 1526-8004. 
premature ovarian failure, respectively. ${ }^{5}$ Oocytes also promote the primary-to-secondary and preantral-to-antral follicle transitions, ${ }^{6-11}$ granulosa cell proliferation and differentiation before the luteinizing hormone (LH) surge, ${ }^{12-18}$ and cumulus expansion and ovulation after the LH surge. ${ }^{19-24}$ It appears that oocytes play a dominant role in this bidirectional communication, and the rate of ovarian follicular development is orchestrated by the oocyte's developmental program. ${ }^{25}$

In the past one and a half decades, remarkable progress has been made in understanding how oocytes regulate the development and function of granulosa cells, as well as how they direct the development of ovarian follicles. That oocytes control cumulus cell metabolic functions highlights the most recent advances in this field and is the main focus of this review. Here we first introduce three types of metabolic cooperation between oocytes and cumulus cells_-amino acid uptake, glycolysis, and cholesterol biosynthesis-and then we describe how oocytes regulate these three metabolic processes in cumulus cells and discuss the participation of the three major oocyte-derived paracrine factors: growth differentiation factor 9 (GDF9), bone morphogenetic protein 15 (BMP15), and fibroblast growth factor 8B (FGF8B).

\section{METABOLIC COOPERAVITY BETWEEN OOCYTES AND GRANULOSA CELLS}

\section{Gap Junction-Mediated Coupling between Oocytes and Granulosa Cells}

Oocytes are coupled to companion granulosa cells via membrane specializations known as gap junctions. ${ }^{26}$ In antral follicles, gap junctions couple oocytes and cumulus cells. ${ }^{27}$ The major isoform of connexins that assemble into the gap-junction channels between oocytes and cumulus or preantral granulosa cells is GJA4 (gap junction protein, $\alpha 4$, also commonly known as connexin 37 [Cx37]). Gap junctions are also formed between granulosa cells: mural-mural, mural-cumulus cells, and the major isoform of connexins in these gap junctions is GJA1 (gap junction associated protein, $\alpha 1$, also known as connexin 43 [Cx43]). The properties of gap junctions that allow the direct passage of certain small molecular weight molecules, such as ions (e.g., calcium), metabolites (e.g., pyruvate, nucleic acids, and inositol), amino acids (e.g., alanine, histidine, and leucine), and intracellular signaling molecules (e.g., cAMP [cyclic adenosine monophosphate], cGMP [cyclic guanosine monophosphate], and $\mathrm{IP}_{3}$ [inositol 1,3,5-trisphosphate]) from granulosa cells to oocytes provides a physical basis for metabolic cooperation between oocytes and granulosa cells. Indeed, many known inputs from granulosa cells are directed to oocytes through gap junctions, ${ }^{2}$ and both GJA4 and GJA1 are indispensable for the development of both oocytes and granulosa cells as evidenced by the failure of folliculogenesis in Gja4- and Gja1knockout ovaries. ${ }^{28-30}$ Further studies indicate that the absence of GJA1 from only granulosa cells, or GJA4 from only oocytes, disrupts follicular and oocyte development. ${ }^{31}$ However, the absence of GJA4 from only granulosa cells or absence of GJA1 from only oocytes does not affect either oocyte or follicle development, ${ }^{31}$ although oocyte-specific deletion of GJA1 significantly impairs subsequent blastocyst implantation. ${ }^{32}$ Therefore, expression of GJA4 in oocytes is essential for communication with granulosa cells. Interestingly, although GJA4 differs markedly from GJA1 in biophysical properties and permeability, the function of GJA4 in coupling oocytes with granulosa cells can be replaced experimentally in vivo by overexpression of Gja1 in Gja4-null oocytes with no interruption of normal oogenesis and fertility. ${ }^{33}$

\section{Glycolysis, Amino Acid Uptake, and Cholesterol Biosynthesis: Examples of Metabolic Cooperativity}

Although it was proposed more than a century ago that granulosa cells support oocyte development by providing them with essential nutrients, ${ }^{34}$ the concept of metabolic cooperativity between oocytes and granulosa cells did not emerge until the 1960s when Biggers et al ${ }^{35}$ first documented the inability of denuded mouse oocytes to use glucose as an energy source to support meiotic maturation. Cumulus cell-enclosed oocytes could undergo maturation in medium providing glucose as the only energy source; however, denuded oocytes could only mature when pyruvate was provided in the medium. This indicates that oocytes are deficient in their ability to use glucose as an energy substrate and require cumulus cells to metabolize glucose into products that can be used by oocytes as energy production substrate(s) to support maturation. Others found that cumulus cells can metabolize glucose into pyruvate, which then is provided to oocytes. ${ }^{36,37}$ Although pyruvate produced as a product of glycolysis by cumulus cells could be transferred to oocytes via gap junctions, it is also possible that cumulus cells secrete pyruvate, which is subsequently transported into the oocyte. Indeed, oocytes are rich in members of the SLC16A (MCT) (solute carrier family 16 [monocarboxylic acid transporters]) family of monocarboxylic acid transporters. ${ }^{38}$ However, other cumulus cell products derived from energy metabolic pathways that are not easily transported across cell membranes, including adenosine triphosphate itself, could be transferred to oocytes via gap junctions.

Oocytes metabolize pyruvate through oxidative phosphorylation to produce energy for growth and maturation. ${ }^{35,39,40}$ Indeed, there is a high rate of pyruvate consumption in maturing MI (metaphase I) oocytes as compared with immature or MII (metaphase II) 
oocytes, ${ }^{41}$ and oocyte-specific deletion of Pdha1 (pyruvate dehydrogenase E1 $\alpha 1$ ), a gene encoding an enzyme subunit of pyruvate dehydrogenase complex, resulted in defects in both oocyte meiotic and cytoplasmic maturation. ${ }^{42}$ Therefore, metabolic cooperativity exists between oocytes and cumulus cells in the utilization of glucose: Cumulus cells first metabolize glucose into pyruvate by glycolysis, and then pass it into oocytes, where pyruvate is oxidized to produce energy for use by oocytes. The molecular basis of this metabolic cooperativity has recently been provided by a study in which transcripts encoding key enzymes in glycolytic pathway (i.e., Aldoa [aldolase 1, A isoform], Eno1 [enolase 1, $\alpha$ non-neuron], Ldha [lactate dehydrogenase A], Pfkp [phosphofructokinase, platelet], $P k m 2$ [pyruvate kinase, muscle], and Tpi1 [triosephosphate isomerase 1]) were found to be robustly expressed in cumulus cells but barely detectable in oocytes. ${ }^{43}$ Metabolic cooperativity between cumulus cells and oocytes in glycolysis is probably also operative in other mammalian species, such as the rat, ${ }^{44}$ cattle, ${ }^{45-47}$ rhesus monkey, ${ }^{39}$ and human ${ }^{48}$ because oocytes of these species are also deficient in using glucose, and their cumulus cells have relatively higher levels of glycolytic activity. Interestingly, there is little or no glycolytic activity in amphibian (e.g., frog) oocytes, ${ }^{49}$ and pyruvate, but not glucose, is one of the most effective exogenous energy resources for the in vitro maintenance of Xenopus oocytes. ${ }^{50}$ This suggests that metabolic cooperation could also exist between frog oocytes and the surrounding follicle cells.

Another example of metabolic cooperativity between oocytes and cumulus cells involves the uptake of amino acids. Mouse oocytes cannot efficiently take up some amino acids, such as L-alanine, and require that cumulus cells take them up and then transfer them to oocytes through gap junctions. Colonna and Mangia ${ }^{51}$ reported in 1983 that when cumulus cell-enclosed or cumulus cell-denuded oocytes were cultured in medium containing $\left[{ }^{14} \mathrm{C}\right] \mathrm{L}$-alanine, the amount of radioactivity detected in oocytes was much higher in the cumulus cellenclosed group. Slc38a3 (solute carrier family 38, member 3), a transcript encoding a sodium-coupled neutral amino acid transporter that has high substrate preference for L-alanine, is highly expressed in cumulus cells but not in oocytes or mural granulosa cells. ${ }^{52}$ This result suggests that the lack of expression of the SLC38A family of transporters by oocytes may account for their poor uptake of L-alanine, thus providing a molecular basis for this specific metabolic cooperativity.

Another surprising facet of metabolic cooperativity in cumulus cell-oocyte complexes involves cholesterol biosynthesis, supported by two lines of evidence. ${ }^{53}$ First, quantitative polymerase chain reaction (PCR) and in situ hybridization showed that the expression of seven transcripts encoding enzymes in the cholesterol biosynthesis pathway, Mvk (mevalonate kinase), Pmvk (phosphome- valonate kinase), Fdps (farnesyl diphosphate synthetase), Sqle (squalene epoxidase), Cyp51 (cytochrome P450, family 51), Sc4mol (sterol-C4-methyl oxidase-like), and Ebp (phenylalkylamine $\mathrm{Ca}^{2+}$ antagonist [emopamil] binding protein), are highly expressed in cumulus cells but not oocytes, thus suggesting that mouse oocytes lack the full enzymatic system required for synthesizing cholesterol. Oocytes are probably also unable to take up cholesterol from their micro-environment via receptor-mediated selective uptake of carrier-borne cholesterol because receptors for both high-density lipoprotein (HDL) cholesterol (i.e., SCARB1 [scavenger receptor class B, member 1], also known as SR-BI) and lowdensity lipoprotein (LDL) cholesterol (i.e., LDLR) are not expressed by mouse oocytes. ${ }^{54,55}$ Hence cumulus cells are the source of cholesterol for mouse oocytes. Second, when mouse oocytes were incubated with radiolabeled acetate as the precursor for cholesterol biosynthesis in culture, the levels of radiolabeled cholesterol were barely detected in denuded oocytes, as opposed to oocytes that were enclosed by cumulus cells during culture. Thus a portion of the cholesterol synthesized by cumulus cells is transferred to oocytes. Furthermore, although some cholesterol destined for transfer to oocytes could be taken up initially by cumulus cells, several lines of evidence suggest that cholesterol synthesized by $\mathrm{cu}^{-}$ mulus cells seems to be the main source of oocyte cholesterol. For example, expression of Scarb1 mRNA was barely detected by in situ hybridization in granulosa cells before the LH surge. ${ }^{56}$ Although $S$ carb1 ${ }^{-1}$ female mice are infertile, ${ }^{55}$ infertility of $S c a r b 1^{-/}$females is not caused by the absence of SCARB1 in the ovary but rather indirectly by extraovarian defects resulting from the absence of SCARB1. ${ }^{57}$ Moreover, little LDL cholesterol is present in follicular fluid, ${ }^{58,59}$ and deletion of $L d l r$ does not affect fertility in mice. ${ }^{60}$ All lines of evidence thus suggest that mouse oocytes are unable to synthesize cholesterol from acetate or take up cholesterol via receptor-mediated selective uptake of carrier-borne cholesterol, and they require cumulus cells to synthesize and provide cholesterol to them.

\section{OOCYTES CONTROL METABOLIC ACTIVITIES IN GRANULOSA CELLS}

\section{Oocytes Promote Expression of Transcripts Encoding Enzymes Involved in Some Metabolic Functions}

The hallmark of the transition of preantral follicles to antral follicles is the formation of two populations of granulosa cells with distinct characteristics and functions-mural granulosa cells and cumulus cells. Whereas mural granulosa cells principally fulfill an endocrine role by producing steroid hormones and various other ligands, cumulus cells play a supporting role for oocyte 
development. Two opposing gradients of "morphogenic" signals, follicle-stimulating hormone (FSH) and oocytederived paracrine factors, are important determinants of mural and cumulus cell lineages and drive differential expression of genes characteristic of either mural or cumulus cell phenotypes. ${ }^{6,7}$ The expression of transcripts at steady-state levels that are higher or lower in cumulus cells relative to mural granulosa cells was hypothesized to be due to their proximity to the oocyte. ${ }^{6,7,61}$

We have used a variety of molecular and genomic approaches, such as suppression subtractive hybridization and microarray analyses, to search for genes that are more highly expressed in cumulus cells than mural granulosa cells, which led to the identification of transcripts encoding key enzymes for glycolysis (i.e., Aldoa, Eno1, Ldha, Pfkp, Pkm2, and Tpi1) and amino acid transporter (i.e., Slc38a3). ${ }^{43,52}$ The higher levels of expression of these transcripts in cumulus cells were confirmed by mRNA in situ hybridization, thus suggesting that oocytes may influence the expression of these transcripts and the corresponding metabolic processes in cumulus cells. ${ }^{43,52}$ This possibility was tested in vitro by comparing the expression of the transcripts already mentioned, as well as glycolytic activity and amino acid uptake, in cumulus cells derived from cultured cumulusoocyte complexes (COCs) and complexes with their oocytes microsurgically removed (oocytectomy [OOX]) before culture. OOX caused dramatic reduction in the levels of Aldoa, Eno1, Ldha, Pfkp, Pkm2, Tpi1, and Slc38a3 in cumulus cells, suggesting that the presence of oocytes is essential for promoting the higher levels of expression of these transcripts in cumulus cells. Furthermore, glycolytic activity and the uptake of radio-labeled L-alanine (a substrate preferentially transported by SLC38A3) were also greatly reduced in OOX cumulus cells, confirming the biological consequence of the reduction of the expression of the corresponding transcripts. When OOX cumulus cells were co-cultured with fully grown oocytes isolated from large antral follicles, levels of expression of transcripts encoding enzymes for glycolysis and the amino acid transporter, as well as glycolytic activity and uptake of radiolabeled L-alanine into cumulus cells, were restored to the levels in the intact COC-cumulus cells. ${ }^{43,52}$ Thus oocytes promote these two metabolic activities in cumulus cells via paracrine signaling mechanisms. Interestingly, partially grown oocytes isolated from late secondary follicles do not promote the expression of Slc38a3; ${ }^{52}$ nor do they promote glycolytic activity ${ }^{43}$ or radiolabeled L-alanine uptake $^{52}$ by OOX cumulus cells. This may reflect relatively lower demand for metabolites by these much smaller oocytes, and the basal metabolic activity of granulosa cells at this stage follicular development may be sufficient to meet the oocytes' requirements.

The role of oocytes in the regulation of cumulus cell glycolysis has also been studied in cattle, where some controversy exists. In one study, denuded bovine oocytes were found unable to carry out glycolysis, whereas high glycolytic activity was found in cumulus-oocyte complexes, suggesting the existence of metabolic cooperativity for glycolysis between bovine oocytes and cumulus cells. ${ }^{62}$ Glycolytic activity was reduced in cumulus cells when oocytes were removed from the complexes, evidence that bovine oocytes promote glycolysis in bovine cumulus cells. ${ }^{62}$ In contrast, in another study, Sutton et $\mathrm{al}^{63}$ did not detect a significant metabolic difference in consumption of glucose by bovine cumulus cells between cumulus-oocyte complexes, OOX cumulus cells, and OOX cumulus cells co-cultured with oocytes. Despite the potential species-specific differences between mouse and bovine oocytes, such as those reported for the role of oocytes in enabling cumulus expansion after LH surge, ${ }^{64,65}$ differences in methodologies must be considered. For example, the former study ${ }^{62}$ used radiolabeled glucose $\left(\mathrm{D}-\left[5^{3} \mathrm{H}\right]\right.$ glucose $)$ as the substrate, and glycolysis was measured as the production of radiolabeled $\mathrm{H}_{2} \mathrm{O}$, the same method as that used in study with mouse cells; whereas the latter ${ }^{63}$ just measured the changes in the absolute amount of glucose in the medium using microfluorometric assay. Nevertheless, more studies are apparently necessary to resolve this discrepancy by simultaneously using these two methods to measure glycolytic activity in bovine cumulus cells under various experimental conditions. The potential role of oocytes in regulation of glycolysis and amino acid uptake by cumulus cells in other mammalian species, including human, is not known.

Oocytes promote cholesterol biosynthesis in mouse cumulus cells. ${ }^{53}$ The expression of key transcripts encoding enzymes required for cholesterol biosynthesis was found, by mRNA in situ hybridization, to be at much higher steady-state levels in cumulus cells than in mural granulosa cells. ${ }^{53}$ OOX resulted in dramatic reduction in expression of almost all of the transcripts encoding enzymes for cholesterol biosynthesis, as well as de novo cholesterol biosynthesis in cumulus cells. ${ }^{53}$ These data thus indicate that oocytes promote cholesterol biosynthesis in cumulus cells, at least in part, by promoting the expression of transcripts encoding enzymes in this pathway. Co-culture of OOX cumulus cells with fully grown oocytes restored expression of the transcripts in OOX cumulus cells to levels comparable to those in cumulus cells of intact COCs, thus indicating that oocytes promote expression of these transcripts via secretion of paracrine regulatory factors. However, $\mathrm{co}^{-}$ culture with fully grown oocytes did not completely restore the levels of de novo synthesized cholesterol in OOX cumulus cells, suggesting the participation of juxtacrine signaling mechanisms in oocyte regulation of cholesterol biosynthesis in cumulus cells. ${ }^{53}$

Taking all this evidence together (as illustrated in Fig. 1), oocytes control cumulus cell metabolism in part 
by promoting the expression of transcripts involved in metabolic processes deficient in oocytes. Oocytes achieve this goal by secreting paracrine factors that act on cumulus cells.

\section{Participation of Oocyte-Derived GDF9, BMP15, and FGF8 in the Control of Metabolic Processes in Cumulus Cells}

Oocytes secrete a "cocktail" of paracrine factors having the potential to affect functions of cumulus cells, and each factor in this cocktail may have specific and/or general targets. Identification of these oocyte-secreted factors and elucidating their targets and mechanisms of action is crucial to our understanding of how oocytes control granulosa cell development and function.

Two closely related members of the transforming growth factor $\beta$ (TGF- $\beta$ ) superfamily, GDF9 and BMP15 (also known as GDF9 $\beta$ ), are expressed robustly in the oocytes of most mammalian species, ${ }^{66}$ and at least in mouse ovaries, their expression is restricted to oocytes. $^{67-69}$ Both GDF9 and BMP15 appear crucial for normal ovarian follicle development and ovulation in all mammalian species studied including mouse, $, 8,70,71$
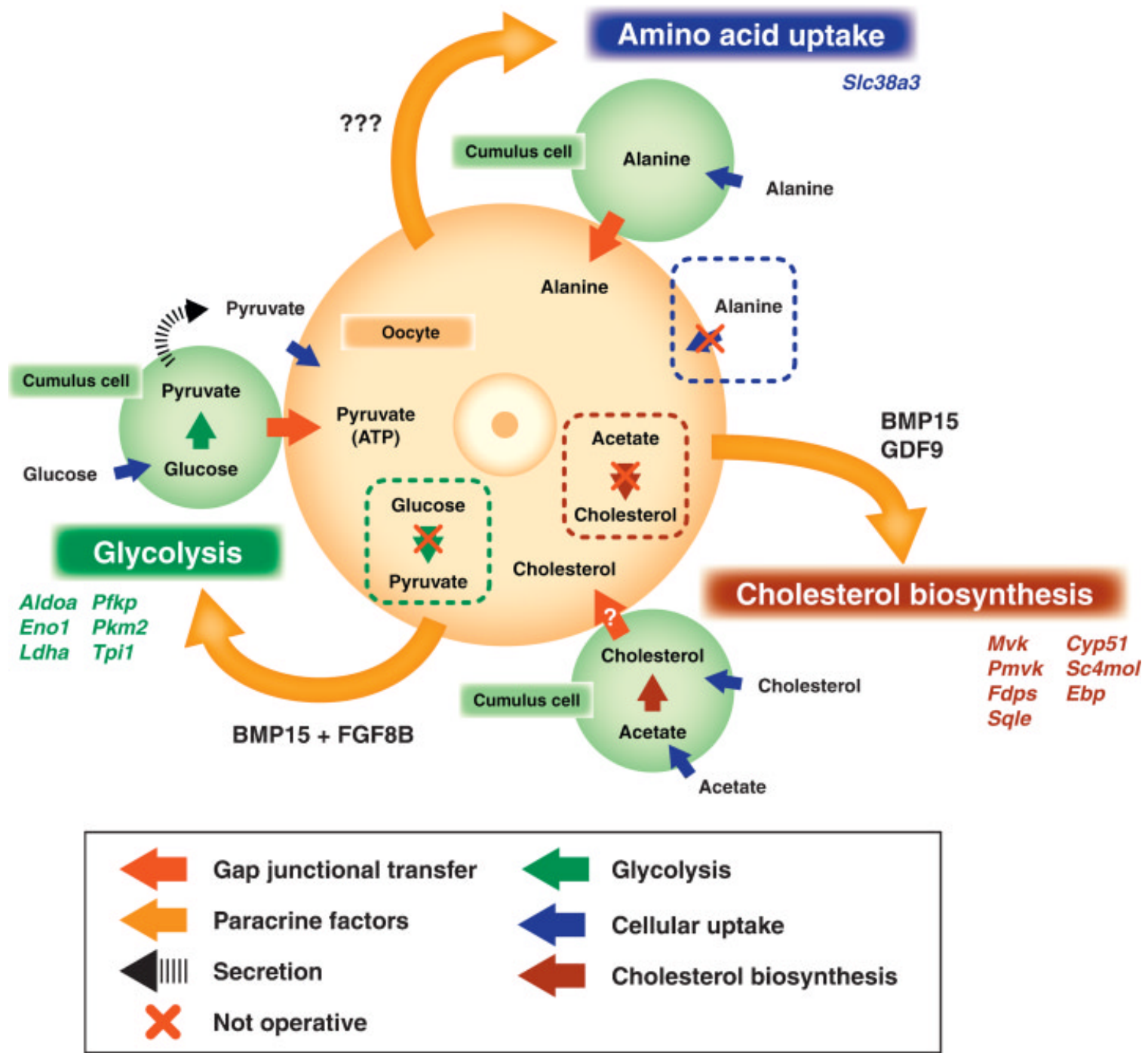

Figure 1 Metabolic cooperativity between oocytes and cumulus cells, and the role of oocyte-derived paracrine factors in promoting metabolism in cumulus cells. Oocytes are deficient in metabolizing glucose by glycolysis, synthesizing cholesterol from acetate, and taking up alanine directly, as compared with cumulus cells. Oocytes obtain products of the glycolysis (e.g., pyruvate) and cholesterol biosynthesis (e.g., cholesterol) pathway, as well as alanine from cumulus cells. Oocytes, via secreting paracrine factors, promote these metabolic processes in cumulus cells by promoting the expression of transcripts encoding key enzymes in the corresponding pathways, as well as the expression S/c38a3 encoding an amino acid transporter for L-alanine. Growth differentiation factor 9 (GDF9) and bone morphogenetic protein 15 (BMP15) are involved in promoting cholesterol biosynthesis in cumulus cells, and cooperation between BMP15 and fibroblast growth factors (FGFs) are required for promoting glycolysis. Which oocyte-derived paracrine factor(s) participate in the induction of S/c38a3 expression, as well as L-alanine uptake by cumulus cells, are unknown. ATP, adenosine triphosphate; FGF8B, fibroblast growth factor 8B. 
sheep, ${ }^{9,72,73}$ and human, ${ }^{74-77}$ as revealed by studies with genetically targeted or spontaneous mutant models. In the mouse, Gdf9 null $\left(G d f g^{-/-}\right)$females are infertile, as compared with their wild type and heterozygous $\left(G d f 9^{+\prime-}\right)$ female litter mates, and this is caused by the inability of cuboidal granulosa cell to proliferate in primary follicles. ${ }^{8,70}$ Although deletion of Bmp15 $\left(B m p 15^{-1-}\right)$ causes female-specific subfertility with the defects in ovulation and fertilization, ${ }^{71}$ more dramatic reduction of fertility occurs in double-mutant (hereafter DM) $B m p 15^{-/-} G d f 9^{+/-}$females owing, at least in part, to the fragility of the ovulated cumuli oophori and the instability of the matrix formed around them. ${ }^{71}$ Subsequent studies with the DM cumulus-oocyte complexes revealed that DM cumulus cells develop abnormally before the LH surge, as cumulus expansion is compromised in vitro despite appropriate stimulation by hormones and expansion-enabling factors. ${ }^{23}$ Thus BMP15 and GDF9 cooperate before the LH surge to promote normal differentiation of cumulus cells. In contradiction, two studies suggest that BMP15 has no role in folliculogenesis until just before ovulation to induce cumulus expansion. ${ }^{78,79}$ This conclusion was based on higher levels of the mature form of BMP15 protein detected by Western blot in oocytes at 9 hours after human chorionic gonadotropin (hCG) injection, ${ }^{79}$ and strong immunostaining of BMP15 was seen in the extracellular spaces of some, but not all, expanded cumulus oophorus at 24 hours after hCG administration. ${ }^{78}$ The detection of higher levels of bioactive BMP15 in oocytes at the time just before ovulation is consistent with the observation that cumuli oophori ovulated in $B m p 15^{-}$ ${ }^{-}$Gdf $9^{+/-}$DM females are fragile and unstable, ${ }^{71}$ thus providing more biochemical evidence for the role of BMP15 in supporting cumulus expansion. However, cumulus expansion does occur in Bmp15-null females. $^{23,71}$ This suggests that BMP15 is not the only oocyte-derived factor responsible for promoting $\mathrm{cu}^{-}$ mulus expansion. Nevertheless, despite finding higher levels of a mature form of BMP15 protein in oocytes several hours after the LH surge, lower levels were detected in oocytes before the surge. ${ }^{79}$ However, although the levels of bioactive BMP15 detected in oocytes before the LH surge are low, this does not exclude important functions for BMP15 before the surge. Oocyte-specific overexpression of the mature form of mouse BMP15 in vivo induces accelerated follicle growth with decreased primary follicles and an increase in secondary follicles, as well as an increased mitotic index in granulosa cells, indicating that BMP15 can function in early stages of follicular development before the LH surge. ${ }^{80}$ Furthermore, we have strong evidence (see later for more details) that BMP15 participates in the regulation of cumulus cell development and function before the LH surge by promoting metabolism in cumulus cells. ${ }^{53}$
To reveal potential roles of BMP15 and/or GDF9 in the regulation of cumulus cell development and function before the LH surge, we compared the transcriptomes of $B m p 15^{-1-}$ and DM mutant cumulus cells with those of wild type (WT). ${ }^{53}$ Significant changes in the expression of a large number of transcripts in Bmp15 $15^{-/}$and DM cumulus cells were found before the stimulation of cumulus expansion, reflecting profound effects of BMP15 and GDF9 on cumulus cell development and function. There were 5332 transcripts significantly different in the $B m p 15^{-/-}$versus WT comparison, 7640 in the DM versus WT comparison, and 2651 in the DM vs $B m p 15^{-1-}$ comparison. The expression of 744 transcripts was changed in all three comparisons, which can be considered to represent the transcripts most highly regulated in cumulus cells by BMP15 and GDF9. Bioinformatics analyses using Ingenuity Pathways Analysis (IPA) (Ingenuity Systems, Inc., Redwood City, CA) was performed on the commonly changed 744 transcripts to reveal themes in the biochemical pathways affected in mutant cumulus cells. To our surprise, the most strongly affected pathways were metabolic: glycolysis, sterol biosynthesis, inositol metabolism, and pentose phosphate, thus implicating BMP15 and GDF9 in the control of cumulus cell metabolism before the LH surge. Accordingly, we investigated the role of BMP15 and GDF9 in the regulation of cholesterol biosynthesis and glycolysis in cumulus cells. Most of the transcripts encoding enzymes in both pathways were significantly downregulated in $B m p 15^{-/-}$ cumulus cells, which was correlated with the dramatic reduction in the levels of de novo synthesized cholesterol and glycolytic activity in Bmp15 $15^{-1-}$ cumulus cells..$^{53,81}$ Furthermore, $B m p 15^{-1-}$ oocytes failed to promote the expression of transcripts for cholesterol biosynthesis and glycolysis, as well as glycolytic activity, in WT-OOX cumulus cells $\left({ }^{81}\right.$; and our unpublished data). These data cumulatively support the participation of BMP15 in promoting cholesterol biosynthesis and glycolysis in $\mathrm{cu}^{-}$ mulus cells before the LH surge. The more dramatic reduction in the expression of transcripts encoding enzymes in cholesterol biosynthesis pathway and the levels of de novo synthesized cholesterol in DM cumulus cells, as compared with $B m p 15^{-/-}$cumulus cells, indicates that GDF9 also participates in promoting cholesterol biosynthesis in cumulus cells before the LH surge. ${ }^{53}$ Furthermore, associated with the reduction of de novo synthesized cholesterol in DM cumulus cells, less cholesterol was transferred to DM oocytes, thus indicating that BMP 15 and GDF9 promote cholesterol biosynthesis in cumulus cells. ${ }^{53}$ However, GDF9 does not appear to be involved in the regulation of glycolysis in cumulus cells because recombinant GDF9 either alone or in combination with BMP15 did not promote the expression of glycolytic transcripts or glycolysis by WT-OOX cumulus cells. ${ }^{81}$ Instead, another oocyte-derived factor, fibroblast 
growth factor 8B (FGF8B), was found to participate in the control of cumulus cell glycolysis. FGF8 is highly expressed in oocytes of several mammalian species; ${ }^{81-84}$ however, its role in follicular development was unknown. Although neither FGF8B nor BMP15 alone promote expression of glycolytic transcripts in OOX cumulus cells, the combination of both growth factors can significantly promote the expression of glycolytic transcripts and glycolysis in OOX cumulus cells. ${ }^{81}$ Furthermore, SU5402, a specific inhibitor of FGFR-dependent protein kinase activity, inhibited the WT oocyte-promoted expression of glycolytic transcripts in OOX cumulus cells. ${ }^{81}$ Therefore, FGF8B plays an important role in the regulation of cumulus cell development and function by cooperating with BMP15 to promote glycolysis in $\mathrm{cu}^{-}$ mulus. Unlike glycolysis and cholesterol biosynthesis, the specific uptake of $\mathrm{L}$-alanine may not be regulated by BMP15 or GDF9 because the steady-state level of Slc38a3 mRNA was not downregulated in either $B m p 15^{-1-}$ or DM cumulus cells (our unpublished data). The participation of FGF8B in the control of $\mathrm{L}^{-}$ alanine uptake and cholesterol biosynthesis by cumulus cells has not been examined. Figure 1 illustrates a model summarizing participation of BMP15, GDF9, and FGFs in the control of cumulus cell metabolism.

\section{Why Do Oocytes Control Cumulus Cell Metabolism?}

Because oocytes themselves are unable to take up L-alanine or synthesize cholesterol from acetate and poorly metabolize glucose for energy production, they obtain these amino acids and products of cholesterol biosynthesis and glycolysis, which are essential for their development and function, from cumulus cells. We therefore hypothesize that one major reason for oocyte outsourcing of metabolic functions to cumulus cells is to compensate for the oocyte's deficiencies. Oocytes achieve this goal in part by promoting the expression of the transcripts involved in these metabolic pathways in the companion somatic cells, the cumulus cells.

Fully-grown oocytes are one of the largest cells in the body with the greatest volume-to-surface ratio. The cumulus cell plasma membranes could be considered as an extension of the oocyte membrane to facilitate the acquisition of exogenous nutrients by oocytes. Moreover, it may be an advantage for oocytes to focus on anabolic metabolism in preparation for early embryonic development. Outsourcing catabolic metabolism, such as glycolysis, to cumulus cells may also help the oocyte maintain a relatively quiescent status of catabolism, thus reducing the levels of oxidative stress potentially harmful for oocyte quality. ${ }^{85}$ Interestingly, outsourcing metabolism to follicle cells may be an evolutionarily conserved phenomenon across most if not all of the animal species. For example, in low animal species such as insects, birds, and amphibians, the major form of nutrient stored in oocytes is yolk protein, which is derived from specific uptake of the protein vitellogenin (VTG) from the maternal bloodstream and is essential for support of early embryonic development. VTG uptake by oocytes requires the presence of surrounding follicle cells and the gap junction coupling between oocytes and follicle cells. ${ }^{86-88}$ VTG is taken up by pinocytosis in frogs and fish.

Another important goal for oocytes control of metabolism in granulosa cells is probably to participate in regulating the rate of ovarian follicle development. Follicle growth, like the growth of any cell in general, requires sufficient "fuel" supplies (i.e., energy, amino acids, lipids, etc.). Nutritional cues regulated by oocytes, as well as by endocrine, autocrine, and the other paracrine regulatory factors, may directly influence ovarian follicle growth. This is supported by several recent studies showing the participation of the conserved mammalian target of rapamycin (mTOR [mammalian target of rapamycin]) (FRAP1 [FK506 binding protein 12-rapamycin associated protein 1]) protein, an essential component of the energy-sensing pathway, in the control of granulosa cell proliferation ${ }^{89,90}$ and differentiation, ${ }^{91-93}$ as well as follicle growth. ${ }^{90}$ Furthermore, by promoting certain metabolic processes in cumulus cells, oocytes may prevent apoptosis in these cells. ${ }^{94}$ This idea is buttressed by the evidence that inhibition of cholesterol biosynthesis in granulosa cells with statins induces apoptosis, which is prevented by mevalonic acid, an intermediary in the cholesterol biosynthesis pathway. ${ }^{95,96}$ The healthy status of cumulus cells would, in turn, benefit the coordinated development and function of both oocytes and cumulus.

Evidence that strongly supports the hypothesis of oocyte control of the rate of follicle growth is the finding that growing oocytes isolated from the late secondary follicles of 12-day-old mice double the rate of antral follicle formation in vivo when reaggregated with somatic cells isolated from primordial follicles of newborn mice. ${ }^{25}$ Accompanying the accelerated rate of follicle growth is a precocious differentiation of preantral granulosa cells into cumulus and mural granulosa cells, specifically, the early expression of defining cellular and molecular characteristics (i.e., competence to undergo cumulus expansion and expression of $L h c g r$ [luteinizing hormone/choriogonadotropin receptor] mRNA, respectively). ${ }^{25}$ This suggests that in addition to the role of supporting granulosa cell growth, the oocyte also promotes the differentiation of granulosa cells. More direct evidence supporting the role of oocytes in promoting granulosa cell differentiation are findings that oocytes are essential for estrogen amplification of FSH-induced differentiation of mural granulosa cell, ${ }^{15}$ and that oocytes promote the differentiation of cumulus cells from preantral granulosa cells. ${ }^{6,7}$ 


\section{CONCLUSION}

The cell-to-cell interactions just summarized comprise strong evidence of an oocyte-granulosa cell regulatory loop by which complementary signaling and metabolic pathways drive the development and function of both the oocytes and follicular somatic compartments. Although it is clear that GDF9, BMP15, and FGF8B participate in the regulation of some of the metabolic processes in cumulus cells, they apparently do not completely represent the "cocktail" of oocyte-derived factors. Challenges are to discover other possible oocyte-regulated metabolic processes in granulosa cells, as well as the specific oocyte-derived paracrine factors responsible for the regulation. Oocytes express the mRNA or protein of the ligands for other members of the TGF- $\beta$ family, such as TGF- $\beta 2$, TGF- $\beta 3$, BMP6 (bone morphogenetic protein 6), as well as ligands for Notch- and sonic hedgehog-signaling pathways, such as JAG1 and 2 (jagged 1 and 2), and SHH sonic hedgehog). ${ }^{97-99}$ These factors, as well as previously unidentified factors, could participate in the oocyte-granulosa cell regulatory loop and need to be investigated. Resolution of factors driving the regulatory loop, and the processes they control, will affect clinical procedures and practices, such as assessment of oocyte quality, alleviating infertility, and development of new and safer methods of contraception.

\section{ACKNOWLEDGMENTS}

Research described here in the authors' group was funded by the NICHD (HD23839, HD21970, and HD 44416 to John J. Eppig). The authors thank Karen Wigglesworth, Marilyn J. O'Brien, and Frank L. Pendola for the technical assistance for the work published and described here and Dr. Mary Ann Handel for helpful suggestions in the preparation of the manuscript.

\section{REFERENCES}

1. Eppig JJ. Oocyte control of ovarian follicular development and function in mammals. Reproduction 2001;122:829838

2. Buccione R, Schroeder AC, Eppig JJ. Interactions between somatic cells and germ cells throughout mammalian oogenesis. Biol Reprod 1990;43:543-547

3. Eppig JJ, Viveiros MM, Marin Bivens C, De La Fuente R. Regulation of Mammalian Oocyte Maturation. In: Leung PCK, Adashi EY, eds. The Ovary. San Diego, CA: Elsevier Academic Press; 2004:113-129

4. Soyal SM, Amleh A, Dean J. FIG $\alpha$, a germ cell-specific transcription factor required for ovarian follicle formation. Development 2000;127(21):4645-4654

5. Reddy P, Liu L, Adhikari D, et al. Oocyte-specific deletion of Pten causes premature activation of the primordial follicle pool. Science 2008;319(5863):611-613
6. Diaz FJ, Wigglesworth K, Eppig JJ. Oocytes are required for the preantral granulosa cell to cumulus cell transition in mice. Dev Biol 2007;305(1):300-311

7. Diaz FJ, Wigglesworth K, Eppig JJ. Oocytes determine cumulus cell lineage in mouse ovarian follicles. J Cell Sci 2007;120(Pt 8):1330-1340

8. Dong J, Albertini DF, Nishimori K, et al. Growth differentiation factor-9 is required during early ovarian folliculogenesis. Nature 1996;383:531-535

9. Galloway SM, McNatty KP, Cambridge LM, et al. Mutations in an oocyte-derived growth factor gene (BMP15) cause increased ovulation rate and infertility in a dosage-sensitive manner. Nat Genet 2000;25(3):279-283

10. Latham KE, Wigglesworth K, McMenamin M, Eppig JJ. Stage-dependent effects of oocytes and growth differentiation factor 9 on mouse granulosa cell development: advance programming and subsequent control of the transition from preantral secondary follicles to early antral tertiary follicles. Biol Reprod 2004;70(5):1253-1262

11. Orisaka M, Orisaka S, Jiang JY, et al. Growth differentiation factor 9 is antiapoptotic during follicular development from preantral to early antral stage. Mol Endocrinol 2006;20(10): 2456-2468

12. Gilchrist RB, Morrissey MP, Ritter LJ, Armstrong DT. Comparison of oocyte factors and transforming growth factorbeta in the regulation of DNA synthesis in bovine granulosa cells. Mol Cell Endocrinol 2003;201(1-2):87-95

13. Gilchrist RB, Ritter LJ, Armstrong DG. Growth-promoting activity of mouse oocytes is developmentally regulated. Biol Reprod 2000;62(suppl 1):422

14. Gilchrist RB, Ritter LJ, Armstrong DG. Mouse oocyte mitogenic activity is developmentally coordinated throughout folliculogenesis and meiotic maturation. Dev Biol 2001; 240:289-298

15. Otsuka F, Moore RK, Wang X, et al. Essential role of the oocyte in estrogen amplification of follicle-stimulating hormone signaling in granulosa cells. Endocrinology 2005; 146(8):3362-3367

16. Otsuka F, Yao Z, Lee T, et al. Bone morphogenetic protein15. Identification of target cells and biological functions. J Biol Chem 2000;275(50):39523-39528

17. Vanderhyden BC, Telfer EE, Eppig JJ. Mouse oocytes promote proliferation of granulosa cells from preantral and antral follicles in vitro. Biol Reprod 1992;46:1196-1204

18. Vitt UA, Hayashi M, Klein C, Hsueh AJ. Growth differentiation factor-9 stimulates proliferation but suppresses the follicle-stimulating hormone-induced differentiation of cultured granulosa cells from small antral and preovulatory rat follicles. Biol Reprod 2000;62(2):370-377

19. Buccione R, Vanderhyden BC, Caron PJ, Eppig JJ. FSHinduced expansion of the mouse cumulus oophorus in vitro is dependent upon a specific factor(s) secreted by the oocyte. Dev Biol 1990;138:16-25

20. Dragovic RA, Ritter LJ, Schulz SJ, et al. Oocyte-secreted factor activation of SMAD 2/3 signaling enables initiation of mouse cumulus cell expansion. Biol Reprod 2007;76(5): 848-857

21. Joyce IM, Pendola FL, O’Brien M, Eppig JJ. Regulation of prostaglandin-endoperoxide synthase 2 messenger ribonucleic acid expression in mouse granulosa cells during ovulation. Endocrinology 2001;142(7):3187-3197

22. Su YQ, Wigglesworth K, Pendola FL, O’Brien MJ, Eppig JJ. Mitogen-activated protein kinase activity in cumulus cells is 
essential for gonadotropin-induced oocyte meiotic resumption and cumulus expansion in the mouse. Endocrinology 2002;143(6):2221-2232

23. Su YQ, Wu X, O'Brien MJ, et al. Synergistic roles of BMP15 and GDF9 in the development and function of the oocytecumulus cell complex in mice: genetic evidence for an oocytegranulosa cell regulatory loop. Dev Biol 2004;276(1): 64-73

24. Vanderhyden BC, Caron PJ, Buccione R, Eppig JJ. Developmental pattern of the secretion of cumulus-expansion enabling factor by mouse oocytes and the role of oocytes in promoting granulosa cell differentiation. Dev Biol 1990;140: 307-317

25. Eppig JJ, Wigglesworth K, Pendola FL. The mammalian oocyte orchestrates the rate of ovarian follicular development. Proc Natl Acad Sci U S A 2002;99:2890-2894

26. Anderson E, Albertini DF. Gap junctions between the oocyte and companion follicle cells in the mammalian ovary. J Cell Biol 1976;71:680-686

27. Albertini DF, Combelles CMH, Benecchi E, Carabatsos MJ. Cellular basis for paracrine regulation of ovarian follicle development. Reproduction 2001;121(5):647-653

28. Ackert CL, Gittens JE, O’Brien MJ, Eppig JJ, Kidder GM. Intercellular communication via connexin43 gap junctions is required for ovarian folliculogenesis in the mouse. Dev Biol 2001;233(2):258-270

29. Juneja SC, Barr KJ, Enders GC, Kidder GM. Defects in the germ line and gonads of mice lacking connexin43. Biol Reprod 1999;60(5):1263-1270

30. Simon AM, Goodenough DA, Li E, Paul DL. Female infertility in mice lacking connexin 37. Nature 1997; 385(6616):525-529

31. Gittens JE, Kidder GM. Differential contributions of connexin37 and connexin43 to oogenesis revealed in chimeric reaggregated mouse ovaries. J Cell Sci 2005;118(Pt 21): 5071-5078

32. Gershon E, Plaks V, Aharon I, et al. Oocyte-directed depletion of connexin43 using the Cre-LoxP system leads to subfertility in female mice. Dev Biol 2008;313(1):1-12

33. Li TY, Colley D, Barr KJ, Yee SP, Kidder GM. Rescue of oogenesis in $\mathrm{Cx} 37$-null mutant mice by oocyte-specific replacement with Cx43. J Cell Sci 2007;120(Pt 23):4117-4125

34. Paladino G. I ponti intercellulari tra l'uovo ovarico e le cellule follicolari e la formazione della zona pellucida. Anat Anz 1890;15:254-259

35. Biggers JD, Whittingham DG, Donahue RP. The pattern of energy metabolism in the mouse oocyte and zygote. Proc Natl Acad Sci U S A 1967;58:560-567

36. Donahue RP, Stern S. Follicular cell support of oocyte maturation: production of pyruvate in vitro. J Reprod Fertil 1968;17(2):395-398

37. Leese HJ, Barton AM. Production of pyruvate by isolated mouse cumulus cells. J Exp Zool 1985;234(2):231-236

38. Herubel F, El Mouatassim S, Guerin P, Frydman R, Menezo Y. Genetic expression of monocarboxylate transporters during human and murine oocyte maturation and early embryonic development. Zygote 2002;10(2):175181

39. Brinster RL. Oxidation of pyruvate and glucose by oocytes of the mouse and rhesus monkey. J Reprod Fertil 1971;24(2): 187-191

40. Eppig JJ. Analysis of mouse oogenesis in vitro. Oocyte isolation and the utilization of exogenous energy sources by growing oocytes. J Exp Zool 1976;198:375-386
41. Downs SM, Humpherson PG, Leese HJ. Pyruvate utilization by mouse oocytes is influenced by meiotic status and the cumulus oophorus. Mol Reprod Dev 2002;62(1):113-123

42. Johnson MT, Freeman EA, Gardner DK, Hunt PA. Oxidative metabolism of pyruvate is required for meiotic maturation of murine oocytes in vivo. Biol Reprod 2007; 77(1):2-8

43. Sugiura K, Pendola FL, Eppig JJ. Oocyte control of metabolic cooperativity between oocytes and companion granulosa cells: energy metabolism. Dev Biol 2005;279(1): 20-30

44. Tsutsumi O, Satoh K, Taketani Y, Kato T. Determination of enzyme activities of energy metabolism in the maturing rat oocyte. Mol Reprod Dev 1992;33(3):333-337

45. Cetica P, Pintos L, Dalvit G, Beconi M. Activity of key enzymes involved in glucose and triglyceride catabolism during bovine oocyte maturation in vitro. Reproduction 2002;124(5):675-681

46. Rieger D, Loskutoff NM. Changes in the metabolism of glucose, pyruvate, glutamine and glycine during maturation of cattle oocytes in vitro. J Reprod Fertil 1994;100(1):257262

47. Rushmer RA, Brinster RL. Carbon dioxide production from pyruvate and glucose by bovine oocytes. Exp Cell Res 1973;82(2):252-254

48. Tsutsumi O, Yano T, Satoh K, Mizuno M, Kato T. Studies of hexokinase activity in human and mouse oocyte. Am J Obstet Gynecol 1990;162(5):1301-1304

49. Dworkin MB, Dworkin-Rastl E. Carbon metabolism in early amphibian embryos. Trends Biochem Sci 1991;16(6):229234

50. Eppig JJ, Steckman ML. Comparison of exogenous energy sources for in vitro maintenance of follicle cell-free Xenopus laevis oocytes. In Vitro 1976;12(3):173-179

51. Colonna R, Mangia F. Mechanisms of amino acid uptake in cumulus-enclosed mouse oocytes. Biol Reprod 1983;28:797803

52. Eppig JJ, Pendola FL, Wigglesworth K, Pendola JK. Mouse oocytes regulate metabolic cooperativity between granulosa cells and oocytes: amino acid transport. Biol Reprod 2005;73(2):351-357

53. Su YQ, Sugiura K, Wigglesworth K, et al. Oocyte regulation of metabolic cooperativity between mouse cumulus cells and oocytes: BMP15 and GDF9 control cholesterol biosynthesis in cumulus cells. Development 2008;135(1):111-121

54. Sato N, Kawamura K, Fukuda J, et al. Expression of LDL receptor and uptake of LDL in mouse preimplantation embryos. Mol Cell Endocrinol 2003;202(1-2):191-194

55. Trigatti B, Rayburn H, Vinals M, et al. Influence of the high density lipoprotein receptor SR-BI on reproductive and cardiovascular pathophysiology. Proc Natl Acad Sci U S A 1999;96(16):9322-9327

56. Li X, Peegel H, Menon KM. In situ hybridization of high density lipoprotein (scavenger, type 1) receptor messenger ribonucleic acid (mRNA) during folliculogenesis and luteinization: evidence for mRNA expression and induction by human chorionic gonadotropin specifically in cell types that use cholesterol for steroidogenesis. Endocrinology 1998; 139(7):3043-3049

57. Miettinen HE, Rayburn H, Krieger M. Abnormal lipoprotein metabolism and reversible female infertility in HDL receptor (SR-BI)-deficient mice. J Clin Invest 2001;108(11): $1717-1722$ 
58. Perret BP, Parinaud J, Ribbes H, et al. Lipoprotein and phospholipid distribution in human follicular fluids. Fertil Steril 1985;43(3):405-409

59. Simpson ER, Rochelle DB, Carr BR, MacDonald PC. Plasma lipoproteins in follicular fluid of human ovaries. J Clin Endocrinol Metab 1980;51(6):1469-1471

60. Ishibashi S, Brown MS, Goldstein JL, et al. Hypercholesterolemia in low density lipoprotein receptor knockout mice and its reversal by adenovirus-mediated gene delivery. J Clin Invest 1993;92(2):883-893

61. Sugiura K, Eppig JJ. Control of metabolic cooperativity between oocytes and their companion granulosa cells by mouse oocytes. Reprod Fertil Dev 2005;17(7):667-674

62. Zuelke KA, Brackett BG. Effects of luteinizing hormone on glucose metabolism in cumulus-enclosed bovine oocytes matured in vitro. Endocrinology 1992;131(6):2690 2696

63. Sutton ML, Cetica PD, Beconi MT, et al. Influence of oocyte-secreted factors and culture duration on the metabolic activity of bovine cumulus cell complexes. Reproduction 2003;126(1):27-34

64. Gilchrist RB, Ritter LJ, Armstrong DT. Oocyte-somatic cell interactions during follicle development in mammals. Anim Reprod Sci 2004;82-83:431-446

65. Ralph JH, Telfer EE, Wilmut I. Bovine cumulus cell expansion does not depend on the presence of an oocyte secreted factor. Mol Reprod Dev 1995;42(2):248-253

66. Juengel JL, McNatty KP. The role of proteins of the transforming growth factor-beta superfamily in the intraovarian regulation of follicular development. Hum Reprod Update 2005;11(2):143-160

67. Dube JL, Wang P, Elvin J, et al. The bone morphogenetic protein 15 gene is $\mathrm{X}$-linked and expressed in oocytes. Mol Endocrinol 1998;12(12):1809-1817

68. McGrath SA, Esquela AF, Lee SJ. Oocyte-specific expression of growth differentiation factor-9. Mol Endocrinol 1995;9(1):131-136

69. McPherron AC, Lee SJ. GDF-3 and GDF-9: two new members of the transforming growth factor-beta superfamily containing a novel pattern of cysteines. J Biol Chem 1993; 268(5):3444-3449

70. Elvin JA, Yan CN, Wang P, Nishimori K, Matzuk MM. Molecular characterization of the follicle defects in the growth differentiation factor 9-deficient ovary. Mol Endocrinol 1999;13(6):1018-1034

71. Yan C, Wang P, DeMayo J, et al. Synergistic roles of bone morphogenetic protein 15 and growth differentiation factor 9 in ovarian function. Mol Endocrinol 2001;15(6):854-866

72. Bodin L, Di Pasquale E, Fabre S, et al. A novel mutation in the bone morphogenetic protein 15 gene causing defective protein secretion is associated with both increased ovulation rate and sterility in Lacaune sheep. Endocrinology 2007; 148(1):393-400

73. Juengel JL, Hudson NL, Heath DA, et al. Growth differentiation factor 9 and bone morphogenetic protein 15 are essential for ovarian follicular development in sheep. Biol Reprod 2002;67(6):1777-1789

74. Chand AL, Ponnampalam AP, Harris SE, Winship IM, Shelling AN. Mutational analysis of BMP15 and GDF9 as candidate genes for premature ovarian failure. Fertil Steril 2006;86(4):1009-1012

75. Di Pasquale E, Rossetti R, Marozzi A, et al. Identification of new variants of human BMP15 gene in a large cohort of women with premature ovarian failure. J Clin Endocrinol Metab 2006;91(5):1976-1979

76. Dixit H, Rao LK, Padmalatha VV, et al. Missense mutations in the BMP15 gene are associated with ovarian failure. Hum Genet 2006;119(4):408-415

77. Palmer JS, Zhao ZZ, Hoekstra C, et al. Novel variants in growth differentiation factor 9 in mothers of dizygotic twins. J Clin Endocrinol Metab 2006;91(11):4713-4716

78. Gueripel X, Brun V, Gougeon A. Oocyte bone morphogenetic protein 15 , but not growth differentiation factor 9 , is increased during gonadotropin-induced follicular development in the immature mouse and is associated with cumulus oophorus expansion. Biol Reprod 2006;75(6):836-843

79. Yoshino O, McMahon HE, Sharma S, Shimasaki S. A unique preovulatory expression pattern plays a key role in the physiological functions of BMP-15 in the mouse. Proc Natl Acad Sci U S A 2006;103(28):10678-10683

80. McMahon HE, Hashimoto O, Mellon PL, Shimasaki S. Oocyte-specific overexpression of mouse BMP-15 leads to accelerated folliculogenesis and an early onset of acyclicity in transgenic mice. Endocrinology 2008;149(6):2807-2815

81. Sugiura K, Su YQ Diaz FJ, et al. Oocyte-derived BMP15 and FGFs cooperate to promote glycolysis in cumulus cells. Development 2007;134(14):2593-2603

82. Buratini J Jr, Teixeira AB, Costa IB, et al. Expression of fibroblast growth factor-8 and regulation of cognate receptors, fibroblast growth factor receptor-3c and -4 , in bovine antral follicles. Reproduction 2005;130(3):343-350

83. Valve E, Penttila TL, Paranko J, Harkonen P. FGF-8 is expressed during specific phases of rodent oocyte and spermatogonium development. Biochem Biophys Res Commun 1997;232(1):173-177

84. van Wezel IL, Umapathysivam K, Tilley WD, Rodgers RJ. Immunohistochemical localization of basic fibroblast growth factor in bovine ovarian follicles. Mol Cell Endocrinol 1995;115(2):133-140

85. Tamura H, Takasaki A, Miwa I, et al. Oxidative stress impairs oocyte quality and melatonin protects oocytes from free radical damage and improves fertilization rate. J Pineal Res 2008;44(3):280-287

86. Ito Y, Kihara M, Nakamura E, Yonezawa S, Yoshizaki N. Vitellogenin transport and yolk formation in the quail ovary. Zoolog Sci 2003;20(6):717-726

87. Monaco ME, Villecco EI, Sanchez SS. Implication of gap junction coupling in amphibian vitellogenin uptake. Zygote 2007;15(2):149-157

88. Waksmonski SL, Woodruff RI. For uptake of yolk precursors, epithelial cell-oocyte gap junctional communication is required by insects representing six different orders. J Insect Physiol 2002;48(6):667-675

89. Kayampilly PP, Menon KM. Follicle-stimulating hormone increases tuberin phosphorylation and mammalian target of rapamycin signaling through an extracellular signal-regulated kinase-dependent pathway in rat granulosa cells. Endocrinology 2007;148(8):3950-3957

90. Yaba A, Bianchi V, Borini A, Johnson J. A putative mitotic checkpoint dependent on mTOR function controls cell proliferation and survival in ovarian granulosa cells. Reprod Sci 2008;15(2):128-138

91. Alam H, Maizels ET, Park Y, et al. Follicle-stimulating hormone activation of hypoxia-inducible factor- 1 by the phosphatidylinositol 3-kinase/AKT/Ras homolog enriched in brain (Rheb)/mammalian target of rapamycin (mTOR) path- 
way is necessary for induction of select protein markers of follicular differentiation. J Biol Chem 2004;279(19): 1943119440

92. Chen YJ, Hsiao PW, Lee MT, et al. Interplay of PI3K and cAMP/PKA signaling, and rapamycin-hypersensitivity in TGFbeta1 enhancement of FSH-stimulated steroidogenesis in rat ovarian granulosa cells. J Endocrinol 2007;192(2):405-419

93. Hunzicker-Dunn M, Maizels ET. FSH signaling pathways in immature granulosa cells that regulate target gene expression: branching out from protein kinase A. Cell Signal 2006;18(9):1351-1359

94. Hussein TS, Froiland DA, Amato F, Thompson JG, Gilchrist $\mathrm{RB}$. Oocytes prevent cumulus cell apoptosis by maintaining a morphogenic paracrine gradient of bone morphogenetic proteins. J Cell Sci 2005;118(Pt 22):5257-5268

95. Rung E, Friberg PA, Bergh C, Billig H. Depletion of substrates for protein prenylation increases apoptosis in human periovulatory granulosa cells. Mol Reprod Dev 2006;73(10):1277-1283

96. Rung E, Friberg PA, Shao R, et al. Progesterone-receptor antagonists and statins decrease de novo cholesterol synthesis and increase apoptosis in rat and human periovulatory granulosa cells in vitro. Biol Reprod 2005;72(3):538545

97. Johnson J, Espinoza T, McGaughey RW, Rawls A, WilsonRawls J. Notch pathway genes are expressed in mammalian ovarian follicles. Mech Dev 2001;109(2):355-361

98. Pan H, O’Brien MJ, Wigglesworth K, Eppig JJ, Schultz RM. Transcript profiling during mouse oocyte development and the effect of gonadotropin priming and development in vitro. Dev Biol 2005;286(2):493-506

99. Russell MC, Cowan RG, Harman RM, Walker AL, Quirk SM. The hedgehog signaling pathway in the mouse ovary. Biol Reprod 2007;77(2):226-236 